\title{
The Southland Front, New Zealand: Variability and ENSO correlations.
}

\author{
J.Hopkins $^{*, a}$, A.G.P.Shaw ${ }^{\mathrm{b}}$, P.Challenor ${ }^{\mathrm{b}}$ \\ ${ }^{a}$ National Oceanography Centre, Joseph Proudman Building, 6 Brownlow Street, Liverpool, L3 5DA, UK \\ ${ }^{b}$ National Oceanography Centre Southampton, European Way, Southampton, SO14 3ZH, UK
}

\begin{abstract}
A detailed analysis of the Southland Front, a shelf-break system off the southeast coast of South Island, New Zealand is presented. The position, temperature, temperature range and width of the front are determined using a new statistical front detection algorithm and 21 years worth of Advanced Very High Resolution Radiometer satellite sea surface temperature (SST) data. Overall, the front is strongest (highest SST gradients) in the summer and winter, and the across front gradient decreases northward in all seasons, consistent with an equatorward decrease in stability and divergence of isobaths. The surface expression of the front moves further offshore during the winter months and is found closest inshore in the summer. Seasonality of the front is strongly controlled by the annual cycle of subtropical and subantarctic water mass temperatures. Both the temperature and strength of the front are interannually variable, and correlated with the El Niño-Southern Oscillation (ENSO); they both decrease during El Niño, and increase during La Niña events. ENSO indices lead changes in the fronts temperature by up to 6 months. Conversely, the gradient may change up to 6 months in advance of peak ENSO indices. The strength and sign of correlations is seasonally dependent.
\end{abstract}

Key words: Southland Front, front detection, ENSO teleconnections, Subtropical Front

\section{Introduction}

The Subtropical Front (STF) is the broad (400-500 km wide), near continuous hydrographic boundary between relatively warm, saline subtropical gyre waters and cooler,

\footnotetext{
*Corresponding author. J. Hopkins. Email address: jeh200@pol.ac.uk. Tel: +44 (0)151 7954859
} 
fresher subantarctic waters found at approximately $40^{\circ} \mathrm{S}$ in the Southern Ocean (Belkin and Gordon, 1996). New Zealand and its continental shelf lie across the path of the STF, the northern limit of the Antarctic Circumpolar Current system, and present a significant barrier to the front and associated current (Fig. 1). Consequently, west of New Zealand the STF is directed southward toward Snares Shelf (Brodie, 1960; Heath, 1985; Houtman, 1966; Jillett, 1969); it then swings northwards just east of South Island bounded on its western side by an induced northward geostrophic flow of modified warm subtropical water that forms part of the Southland Current (Heath, 1972, 1985; Jillett, 1969). The current is topographically steered along the shelf-break as it flows equatorward up the southeast coast of South Island (Chiswell, 1994; Heath, 1972; Shaw and Vennell, 2001). It then turns eastwards along the Chatham Rise and flows out into the open Pacific Ocean. Fig. 2 is a hydrographic section across the continental shelf at Oamaru, taken on NIWA cruise 3006 in April 1993. The Southland Front is located by the strong horizontal gradients in temperature, salinity and density.

Recent studies report that the Southland Current in fact transports $90 \%$ subantarctic and $10 \%$ subtropical waters (Sutton, 2003). The current is unique in the sense that it flows along a western boundary in the direction opposite to that demanded by Sverdrup theory. Its location and direction are thought to be the result of two processes. First, a westward barotropic current along the southern edge of Bounty Trough (marked in Fig. 1), merging with shallower currents from the southwest to become the Southland Current. Second, and to a lesser extent, remote forcing from the strong, topographically constrained subantarctic abyssal currents to the east of New Zealand (Hurlburt et al., 2008; Tilburg et al., 2002).

The Southland Front and Current are important oceanographic features. They transport heat, salt and momentum into the subtropical convergence zone over the Chatham Rise, a known carbon dioxide sink (Currie and Hunter, 1998, 1999; Murphy et al., 1991). Subantarctic water transported within the Southland Current to the southern flank of the Chatham Rise helps maintain the southern STF across the Pacific (Hurlburt et al., 2008; Sutton, 2001). Elevated productivity along the front, where warm macronutrient-poor, 
and relatively iron-rich subtropical waters mix with cold, macronutrient-rich, but iron and silicate poor subantarctic waters (Boyd et al., 1999; Butler et al., 1992), supports a valuable deep water fish stock (Livingston, 2000; McClatchie et al., 2001). Furthermore, the Southland Current system determines the local oceanographic conditions off the southeast coast of South Island. The presence of cool subantarctic water immediately to the east helps maintain a cooler climate than on North Island (Heath, 1972). Understanding the variability in strength and position of the Southland Front is therefore important from commercial, biological and climatic perspectives.

There is a wealth of literature describing characteristics of the Southland Front (Chiswell, 1994, 1996; Heath, 1972, 1985; Jillett, 1969; Shaw, 1998; Shaw and Vennell, 2001; Uddstrom and Oien, 1999). However, there remains some debate as to its seasonal variability, particularly its gradient. Chiswell (1996) and Shaw and Vennell (2001) found the Southland Front to be strongest (highest gradients) and narrowest in the winter. In contrast, Uddstrom and Oien (1999) found the Southland Front to be strongest in the spring and autumn, and weakest in the winter. The first half of this paper therefore (Section 4) revisits the work of Shaw and Vennell (2001), using a much longer time series of satellite SST images, 21 years as opposed to 3 years. Using a new front detection algorithm, verification and further understanding of the seasonal and spatial variability of the fronts temperature, strength and position is presented, before extending the analysis to interannual time scales.

In the second half of the paper (Section 5) we exploit the long time series to investigate interannual trends. In particular, whether low frequency variability is correlated with the El Niño-Southern Oscillation (ENSO), a dominant mode of coupled interannual ocean-atmosphere variability felt across the globe. It is well documented that air temperatures, SST anomalies and sea level around New Zealand are positively correlated with the Southern Oscillation Index (Goring and Bell, 1999; Gordon, 1986; Mullan, 1998), a measure of ENSO variability. Little is known however about how the strength of the Southland Front may respond to El Niño and La Niña events. Using a front-following algorithm (Shaw and Vennell, 2000a) similar to the method used here, Shaw and Vennell 
(2001) record a decrease in gradient between April 1989 and March 1992, coincident with a decrease in the SOI. Given the often direct relationship between SST gradients and the velocity of geostrophic currents at large scale fronts they suggest that there was a decrease in the velocity of the current associated with the Southland Front during the 1991 El Niño. With the much longer time series available here we investigate whether the strength and temperature of the Southland Front are indeed correlated with ENSO.

\section{Data}

Monthly composite Pathfinder Version 5 AVHRR (Advanced Very High Resolution Radiometer) sea surface temperature data between 1985 and 2005 were obtained through NASA's PO.DAAC POET data server (http://poet.jpl.nasa.gov/), at a spatial resolution of $4 \mathrm{~km}$. Only night-time overpasses were used so as to avoid, as far as possible, any surface skin created by diurnal warming masking the true surface frontal structure. A $1^{\circ}$ by $2.8^{\circ}$ window rotated to lie along the approximate orientation of the Southland Front was extracted from each of the 252 monthly images for analysis (Fig. 3).

A combination of atmospheric and oceanic indices are used as a measure of ENSO variability. The Southern Oscillation Index (SOI), an atmospheric measure of ENSO, is defined as the anomalous sea level pressure in the eastern Pacific at Tahiti minus the sea level pressure in the western Pacific at Darwin, Australia. The oceanic component of ENSO is measured by the Niño 3, Niño 3.4 and Niño 4 SST indices. These consist of the area averaged SST anomalies over the eastern $\left(5^{\circ} \mathrm{N}-5^{\circ} \mathrm{S}, 90-150^{\circ} \mathrm{W}\right)$, east central $\left(5^{\circ} \mathrm{N}-5^{\circ} \mathrm{S}, 120-\right.$ $\left.170^{\circ} \mathrm{W}\right)$ and central $\left(5^{\circ} \mathrm{N}-5^{\circ} \mathrm{S}, 160^{\circ} \mathrm{E}-150^{\circ} \mathrm{W}\right)$ tropical Pacific. A negative SOI and positive regional Niño SST anomaly correspond to an El Niño event, and vice versa for a La Niña. Monthly values of the SOI and regional Niño SST anomalies were downloaded from the NOAA Climate Prediction Center (http://www.cpc.ncep.noaa.gov/data/indices/, September 2007). SOI anomalies are departures from the 1951-1980 base period. 


\section{Methods and data analysis}

\subsection{Front detection}

Estimates of the Southland Front's position, mean temperature, its width and the temperature difference between the subtropical and subantarctic water masses on either side were made from each extracted SST window using a new, weighted local likelihood approach to front detection (Hopkins et al., 2010).

Cross sections of SST observations, Z (Fig. 3), are modelled using an S-shaped function:

$$
\mathbf{Z}=m(\mathbf{Y} ; \boldsymbol{\theta})+\epsilon=\theta_{1}+\theta_{2} \tanh \left[\frac{\mathbf{Y}+\theta_{4}}{\theta_{3}}\right]+\epsilon
$$

$\mathbf{Z}=\left\{z^{(1)}, z^{(2)} \cdots, z^{(n)}\right\}$ is a vector of independently observed temperatures at right angles across the front taken at known distances $\mathbf{Y}=\left\{y^{(1)}, y^{(2)} \cdots, y^{(n)}\right\}$. $\theta_{1}$ is the front's mean temperature; $2 \theta_{2}$ and $2 \theta_{3}$ define the temperature difference and width respectively; $\theta_{4}$ is a translation parameter determining the position of the front within an equiangle arc degree grid. The noise, $\epsilon$, is assumed to be normally distributed where $\epsilon \sim \phi\left(0, \sigma^{2}\right)$. Fig. 3 illustrates the selection of vectors $\mathbf{Z}$ at each point $j$ along the front, and provides a more physical interpretation of the model parameters.

The probability of observations $\mathbf{Z}$ being drawn from a given model front can be expressed in terms of a likelihood function. The unknown model parameters $\boldsymbol{\theta}=\left\{\theta_{1}, \theta_{2}, \theta_{3}, \theta_{4}, \sigma\right\}$ at each point $j$ are determined by maximising a weighted sum of likelihood functions, each corresponding to a different cross section of SST along the extraction window. A Gaussian (normal) function assigns weights to each likelihood contribution based on the distance of observations from the point of estimation $j$. Solving each local likelihood problem at positions $x_{j}$ results in a series of fitted temperature profiles and spatially smooth estimates of frontal position, mean temperature, width and temperature difference along the front. The standard deviation of the Gaussian function controls the spatial smoothness of parameter estimates and is determined automatically using likelihood cross validation (Silverman, 1986). 
Standard errors (SE) are obtained by constructing the variance-covariance matrix of estimates at each position $x_{j}$. This measure of estimation uncertainty is used to calculate: monthly, seasonal and spatial weighted means; the standard error of each weighted mean; and weighted standard deviations. Each estimate is weighted by the inverse of its own variance $\left(1 / S E^{2}\right)$. The thermal gradient, a measure of the fronts strength, is then $\theta_{2 w} / \theta_{3 w}$, where subscript $w$ indicates a weighted mean estimate. Error propagation is subsequently used to calculate the variance associated with the resulting gradient.

Southern hemisphere seasons are used throughout the results and discussion. Summer is taken to be December-February, autumn as March-May, winter as June-August and spring as September-November. Only those estimates receiving a quality flag of 1 were used (see Hopkins (2008) and Hopkins et al. (2010)).

\subsection{Time series analysis}

Spatially averaged monthly anomaly time series of each parameter were created. The annual cycle was removed by subtraction of the 1985-2005 monthly means from the weighted spatial mean of each month. Any linear trend was also removed in order to make each time series stationary. Only very weak linear trends were found suggesting that no global warming signal was present.

An autoregressive model was fitted to each anomaly time series (Priestley, 1992), leaving behind only white noise residuals, in order to remove any autocorrelation and make each point statistically independent. This prewhitening results in correlations that are generally smaller in magnitude than those produced from the original series but, since the residuals have near zero-persistence, the full number of data points is used to estimate significance levels from a Student's $t$-test.

Cross correlation and wavelet analysis are used to investigate interannual variability and possible ENSO teleconnections at the Southland Front. Wavelet analysis is a technique that expands a time series into time-frequency space and provides localised estimates of the amplitude and phase of each spectral component in the data set (Emery and Thomson, 1998; Torrence and Compo, 1998). This is an ideal approach when dealing with atmospheric and oceanic signals where the power within different harmonic constituents 
may change over time. We calculate the wavelet coherence between time series of frontal characteristics and ENSO indices. This can be thought of as a localised cross correlation coefficient in time and frequency space. Regions with high coherence and a consistent phase relationship suggest causality between the two time series and a potential oceanic or atmospheric teleconnection. The statistical significance of any relationship is estimated using Monte Carlo methods. The coherence of 10000 artificially generated data pairs of white noise is used to calculate the significance at each level (Grinsted et al., 2004).

Each finite length time series is zero padded before wavelet analysis to reduce errors introduced at the beginning and end of time series because of the Fourier Transform assumption that the data is cyclic. These discontinuities decrease the amplitude near the edges as more zeros are included in the analysis. The region of the wavelet spectrum in which these edge effects become important is known as the Cone of Influence (COI).

Cross correlation is performed on seasonally averaged and stratified versions of the monthly data. A seasonally stratified summer correlation at zero lag refers to correlations resulting from only summer estimates and indices. A seasonally stratified one season lead reported for the summer represents the correlation between spring ENSO indices and summer frontal characteristics. Likewise, a summer one season lag is for summer frontal estimates correlated with autumn ENSO indices.

\section{Seasonal and spatial variability}

The front detection algorithm allows us to build up a detailed picture of the seasonal and spatial variability of the Southland Front (Figures 4-5 and Table 1). Note that the standard errors of the estimates in Table 1 are all significantly below both the spatial resolution of the data set $(4 \mathrm{~km})$ and the median value of the residual of the Pathfinder SST and match-up buoy measurements $\left(0.1 \pm 0.5^{\circ} \mathrm{C}\right)$ considered per latitudinal band (Kilpatrick et al., 2001). This indicates that the main source of uncertainty is the quality and resolution of data processed rather than estimation errors introduced by the algorithm itself.

Performing one-way ANOVA (Analysis of Variance) tests, using unweighted estimates, 
reveals that there are significant differences in the mean temperature, temperature range, width and position between all seasons at the $99 \%$ confidence interval. The F-statistics are, respectively, $12439,521,325$ and $17\left(\mathrm{df}_{\text {group }}=3, \mathrm{df}_{\text {total }}=12412\right)$.

\subsection{Temperature}

Over the 21 years, the mean temperature $\left(\theta_{1}\right)$ and temperature range $\left(2 \theta_{2}\right)$ of $10.38^{\circ} \mathrm{C}$ and $1.75^{\circ} \mathrm{C}$ respectively, estimated within the extraction window (Fig. 3), are consistent with previous findings (Uddstrom and Oien, 1999; Jillett, 1969; Shaw and Vennell, 2001). With the exception of the summer months an overall decrease in temperature difference across the Southland Front is recorded as it flows northwards (Fig. 5b). There are a number of possible contributing factors to this trend. Firstly, the temperature of subtropical waters within the Southland Current is modified as they flow northwards; they become diluted as a result of mixing at the frontal boundary with cool subantarctic water that is brought to the surface (Butler et al., 1992). Evidence for a northward increase in mixing and instability may be found in the greater number of plumes observed further north (Shaw, 1998). Secondly, subantarctic waters during the spring, summer and autumn may warm more than the subtropical waters as they move equatorward along the continental slope (Shaw and Vennell, 2001). This would promote a northward decrease in temperature difference. Thirdly, entrainment of fresher neritic water into the Southland Current with temperatures generally higher in summer and lower in winter than water immediately offshore, owing to the limited water depth and seasonal temperature variation of river discharge, may also have a role to play. The greatest source of fresh water is from the Clutha River (Murdoch et al., 1990), approximately $60 \mathrm{~km}$ south of the Otago Peninsula, near the start of our measurements and where the Southland Front is closest to the shore. Over this inner shelf region the salinity of Southland Current water can become diluted by Clutha discharge (Jillett, 1969). Entrainment of warm inshore waters into the current could potentially enhance the temperature difference across the front in the summer. Conversely, during the winter, when inshore waters are colder than the subtropical Southland Current waters immediately offshore, the temperature difference may be decreased. Further investigation is needed to establish whether warming/cooling of 
subtropical current waters through mixing with river discharge is a localised event around the Otago Peninsula, or whether outflow from smaller rivers further north is sufficient to have an impact.

During the summer there is a high degree of variability in the temperature difference along the front (Fig. 5b), and the gradual northward decrease seen in other months is not apparent. Notably, there is a sharp increase north of $45^{\circ} \mathrm{S}$, reaching $2.6^{\circ} \mathrm{C}$ at $44.5^{\circ} \mathrm{S}$. Consideration of the differences in the seasonal range and phase of regional surface water mass temperatures helps further explain these trends.

\subsection{Annual SST cycle}

An annual SST cycle using all data for the full period (1985-2005) is fitted at each grid cell. To form this, at least ten data points, including eight different months and at least one point in each season were required. Cells that did not meet these criterion were rejected. The amplitude (half the seasonal range) and phase of the fitted annual cycle is shown in Fig. 6a-b. The absolute gradient of the amplitude and the direction of this gradient are presented in Fig. 6c-d. There are a number of noteworthy features.

A tongue of water with a minimum amplitude $\left(<3^{\circ} \mathrm{C}\right)$ and maximum phase lag $(>34$ days) extends northeast along the shelf-break. Fig. 2 reveals that this is predominantly the cold tongue of subantarctic water previously described by Heath $(1972,1985)$ and Shaw and Vennell (2000b). The doming upwards of isotherms and isopycnals in this region suggests that it is the result of upwelling of cold, deep subantarctic water. As described in Section 1 the location and direction of the Southland Current is thought to be due to deep subantarctic flows impinging on the east coast of South Island. Upwelling of water that has been isolated at depth for a long time will have a much smaller annual range in SST, and take longer to respond to seasonal heating and cooling. The Southland Current transports more subantarctic than subtropical water (Sutton, 2003); it is fitting therefore that the mean 21-year position of the Southland Front ( \pm 1 standard deviation) lies directly along the centre of the cold subantarctic tongue. This supports the fact that front detection using surface SST data is picking out the structure correctly, both horizontally and with depth. 
To the east of the cold tongue lies a water mass with a higher seasonal amplitude in SST $\left(3.5-4.8^{\circ} \mathrm{C}\right)$. This region corresponds to the warm water mass described by Shaw (1998), extending down to 100db (Fig. 2a). The low salinities (Fig. 2b) indicate that it is of subantarctic origin. An isolated surface layer will have a larger annual amplitude in SST than less stratified waters. The origin of this warm water mass is unclear.

Inshore subtropical waters (north of $45^{\circ} \mathrm{S}$ ) have a large annual SST range $\left(>4^{\circ} \mathrm{C}\right)$, and in the summer they heat up earlier and much more than the already cool subantarctic water further offshore (range $2-4^{\circ} \mathrm{C}$ ). The wide range may be explained by considering the limited water depth $(<100 \mathrm{~m}$ in Canterbury Bight). During the summer, turbulence vertically mixes the heat provided by increased insolation down through the mixed layer, depressing the depth of the thermocline. In limited water depths, where the mixed layer may occupy the entire water column, high temperatures are reached. Offshore, where additional heating may be taken up by further expansion of the mixed layer, temperatures remain lower. In the winter, when surface waters experience intense cooling, convective overturning cells replace the colder, denser surface waters with warmer water from depth. In shallower regions this overturning is interrupted, resulting in cooler surface waters compared to those further offshore.

North of $45^{\circ} \mathrm{S}$, during the summer, the large range of the annual SST cycle results in maximal temperature differences between bordering subtropical and subantarctic water. During the winter, more dramatic cooling of inshore waters brings the two temperatures closer together (Fig. 5b), and there is a gradual decrease in an already narrow temperature range. A phase lag of the order 4-6 days between subtropical water and the cold tongue of subantarctic water further contributes to the observed trends, exaggerating the temperature difference in the summer and dampening it in the winter.

The gradient in SST amplitude is low locally around the mean path of the Southland Front (Fig. 6c). It is high on the eastern side of the front where the water depths are minimal and the SST range reaches a maximum. On the western side, there is a narrow band of higher gradients running along the edge of the cold tongue. This feature starts to fade out north of $45^{\circ} \mathrm{S}$ where the front starts to turn eastward. The front follows exactly 
the abrupt change in the direction of the gradient along the centre of the low range tongue (Fig. 6d). To the east, in subtropical and coastal waters, maximum gradients (from high to low) run south-southeast. To the west, in subantarctic waters, the gradient is oriented north-northwest. This gives confidence that our estimate is a true reflection of a boundary where there is a change in processes.

\subsection{Width and gradient}

On average, over the extraction window, the Southland Front is widest (max 2 $\theta_{3}$ ) during the spring $(23.88 \mathrm{~km})$, and narrowest during the winter $(15.12 \mathrm{~km})$ and summer $(15.02$ $\mathrm{km})$. Fig. 5c reveals a northward widening. The most pronounced increase takes place during the autumn from 14 to $38 \mathrm{~km}$ between $45.5^{\circ} \mathrm{S}$ and $44.5^{\circ} \mathrm{S}$ when warm subtropical plumes, with a mean length and width of $48 \pm 23 \mathrm{~km}$ and $18 \pm 10 \mathrm{~km}$ respectively, extending from the Canterbury Bight are most prevalent (Shaw, 1998). These events will promote cross frontal mixing and weaken gradients. Additionally, plumes may not always be well defined in $4 \mathrm{~km}$ resolution images; this results in smoothing and widening of the observed cross front profile. In the winter, northward widening is weaker and is interrupted by a pronounced decrease in width between $45.8^{\circ} \mathrm{S}$ and $45.4^{\circ} \mathrm{S}$.

The only other previous estimates of the Southland Front's width that we are aware of were made by Shaw and Vennell (2001). Their mean three year estimate of $8.36 \mathrm{~km}$ is much narrower than the $18 \mathrm{~km}$ reported here, or the equivalent $19.2 \mathrm{~km}$ three year average. This contrast is primarily a consequence of temporal and spatial blurring that limits the length scale and clarity of features that can be resolved. Shaw and Vennell (2001) analysed daily $1 \mathrm{~km}$ SST images, whereas this study was limited to monthly 4 $\mathrm{km}$ composites which did not resolve many of the finer structures and sharp gradients. Although overestimated, the relative changes in the width remain valid.

The importance of the resolution of data used to estimate frontal characteristics is further demonstrated when the mean gradient is considered. A gradient of $0.097^{\circ} \mathrm{C} \mathrm{km}^{-1}$ is an order of magnitude greater than estimates made by Chiswell (1994) with $46 \mathrm{~km}$ resolution images (max of $0.04^{\circ} \mathrm{C} \mathrm{km}^{-1}$ within the Southland Front), but two to three times weaker than those of Shaw and Vennell (2001) based on a $1 \mathrm{~km}$ data set $\left(0.28^{\circ} \mathrm{C}\right.$ 
$\mathrm{km}^{-1}$ ). As for the width therefore, absolute values of the gradient should be considered as relative to a $4 \mathrm{~km}$ resolution data set.

Overall the gradient of the Southland Front decreases northward (Fig. 5d). Averaged over the extraction window it is strongest during the summer $\left(0.132^{\circ} \mathrm{C} \mathrm{km}^{-1}\right)$ and winter $\left(0.103^{\circ} \mathrm{C} \mathrm{km}^{-1}\right)$, and weakest during the spring $\left(0.079^{\circ} \mathrm{C} \mathrm{km} \mathrm{km}^{-1}\right)$. This contradicts the strong spring and autumn gradients, and weak winter structure reported by Uddstrom and Oien (1999). The seasonal variability seen here is most in agreement with Chiswell (1994, 1996) and Shaw and Vennell (2001) who found gradients at the Southland Front to be strongest during the winter months. One-way ANOVA tests reveal the mean (unweighted) gradients during the spring, summer and winter to all be significantly different from one another at the $99 \%$ confidence interval. There was no significant difference between mean autumn and winter gradients.

There is a change in the character of the front near Oamaru, at approximately $45.5^{\circ} \mathrm{S}$. To the south, the temperature range is not dramatically different between the seasons; the high southerly summer gradients therefore are due to the front being narrowest at this time. North of Oamaru, summer and winter gradients are comparable. Strength in the winter, to the north, is due to the front being narrowest compared to the other seasons. The high southerly summer gradients are not maintained beyond $45.5^{\circ} \mathrm{S}$, and become similar to the winter structure, despite a sharp increase in the temperature difference, because of the overall increase in width northward.

The majority of previous studies of the Southland Front's gradient (Chiswell, 1994; Uddstrom and Oien, 1999) interpret results based only on the variability of subtropical and subantarctic water temperatures. They have not examined spatial and temporal changes in the width of the front that we find here to play an important role. Chiswell (1994, 1996) attributes higher winter gradients to greater annual SST variability of subantarctic water within the Southland Current, and the subsequent enhanced cooling offshore during the winter. We find, however, that the subantarctic waters directly to the east of the Southland Front, and within the cold tongue, have a smaller amplitude than subtropical waters on the shoreward side. We conclude that although the thermal gradient across the 
Southland Front is modulated by the seasonal SST cycle of surrounding water masses, the stability and width of the front introduce important variability.

\subsection{Frontal position and stability}

In support of previous observations (Heath, 1972; Jillett, 1969; Shaw and Vennell, 2001), the front is bathymetrically locked to the shelf-break (between 200 and $1000 \mathrm{~m}$ ), over a median water depth of $560 \mathrm{~m}$. This topographic control is maintained throughout all four seasons. It is located furthest inshore during the summer and moves furthest offshore in the winter (Fig. 4). The seasonal variation in water masses present in the Mernoo Saddle coincides with the annual cycle in frontal position. A wisp of subantarctic water extending northward through the Mernoo Saddle from the cool subantarctic tongue (seen in Fig. 6) pushes furthest west during the summer months. In the winter and early spring a southward extension of subtropical water through the saddle prevents the northward intrusion of subantarctic water (Greig and Gilmour, 1992; Shaw and Vennell, 2000b), and the surface expression of the Southland Front is found furthest offshore (Fig. $4 \mathrm{~b})$.

Seasonal variability in the distribution of surface water masses is an important factor to consider when interpreting the front's position and seasonal characteristics. For example, during the spring and autumn the Southland Current can often be hidden around the Otago Peninsula (Jillett, 1969; Murdoch et al., 1990). Warming and dilution lowers the density of inshore water so that it spreads seawards above the denser subtropical Southland Current water mass. At the same time, surface warming of subantarctic water can lead to a decrease in density and movement shoreward over the top of subtropical water. Southland Current waters extend inshore beneath the neritic water, and offshore under the subantarctic water but can not be seen at the surface (Fig. 7b). The potential masking of Southland Current waters introduces some uncertainty into how well the estimated positions represent the subsurface signature of the Southland Front and the core of the current during these episodes. It may also result in a mis-representation of the strength of the front.

More confidence can be placed in estimates made during the summer and winter 
months. According to Jillett (1969) the subtropical waters of the Southland Current are more visible during the summer; they cover the continental slope and extend seawards beneath the less saline subantarctic water. Note however, that strong stratification and intense patchy warming of the surface mixed layer will introduce a higher degree of variability in parameter estimates. In the winter, isothermal and isohaline conditions mean that all surface water masses are visible (Fig. 7a). Lower weighted standard deviations for parameter estimates made during the winter as opposed to any other season is evidence for more stable and reliable winter results (Table 1).

Masking of subtropical water highlights the importance of using in situ vertical profiles to complement remotely sensed SST data. The mean 21-year position of the Southland Front and its estimated position during April 1993 are marked in Fig. 2. The position of the subsurface structure is well represented by estimates using the surface SST expression of the front.

Stability of the front's position was quantified by the root-mean squared spatial displacement (RMSSD) from the overall mean and seasonal paths (Fig. 8). This may be interpreted as a measure of the meandering intensity (Lee and Cornillon, 1995). Meandering intensity increases as the front flows northward, confirming that topographic control weakens across the Canterbury Bight where isobaths start to diverge. A decrease in stability is supported by an observed increase in plume formation (Shaw, 1998), divergence of flow (Shaw and Vennell, 2001) and intermittent throughflow from the Mernoo Saddle (Greig and Gilmour, 1992; Shaw and Vennell, 2000b). The northward increase in width and decrease in gradient is consistent with greater instability and mixing.

There is little difference in the mean meandering intensity between the spring, summer and autumn. The lowest RMSSD value is observed during the winter and the northward increase does not persist beyond $45.6^{\circ} \mathrm{S}$. Instead, there is a sudden decrease in meandering intensity after which a relatively constant value of $0.07^{\circ}$ is maintained. This increase in stability is coincident with a decrease in width and an increase in gradient at this location (Fig. 5c-d), features that we are unable to explain. 


\section{Interannual variability: ENSO teleconnections}

There is evidence to suggest that remote forcing plays a significant role in the interannual variability of the strength of the Southland Front. Chiswell (1994) finds that the annual modulation in the strength of the front accounts for only $20 \%$ of its variance, and Shaw and Vennell (2001) record a decrease in the gradient and temperature between April 1989 and March 1992, coincident with a decrease in the SOI. Given the often direct relationship between SST gradients and velocity, it was suggested that far field effects on velocity, related to ENSO, might be affecting the front. With a much longer time series the response of the Southland Front to ENSO variability can be further investigated.

Note that only data poleward of $45.5^{\circ} \mathrm{S}$ is used to construct the 21-year time series of frontal gradient. This is to reduce, as far as possible, bias from potential overestimation of the width (Hopkins et al., 2010) over the northern half of the study area where the front starts to swing eastward.

\subsection{ENSO correlations}

Consistent with wider studies of the SST field around New Zealand (Greig et al., 1988; Mullan, 1998; Shaw et al., 1999; Sutton and Roemmich, 2001), Fig. 9a confirms that El Niño episodes are associated with cooling at the Southland Front, and La Niña events with warm anomalies of the order $\pm 1^{\circ} \mathrm{C}$.

There is also strong interannual variability in the gradient of the Southland Front, trends that have to date not been observed. Fig. 9b shows a decrease from 0.12 to $0.07^{\circ} \mathrm{C} \mathrm{km}^{-1}$ between early 1990 and mid 1991, coincident with a drop in the SOI. This is comparable to the decrease of $0.1{ }^{\circ} \mathrm{C} \mathrm{km}^{-1}$ reported by Shaw and Vennell (2001). A weakening of the gradient is also observed during the 1986-87 El Niño, and local gradient minima occur in both 1992 and 1994 during the prolonged period of weak but persistent El Niño events. The pattern of decreasing gradients during negative SOI episodes is broken in 1997-98 when a strong El Niño is accompanied by a sharp increase in strength. There is also some evidence for increased gradients during La Niña events. The front strengthens from mid 1998 to 2001 during a period of persistently positive SOI values. 
Changes in the temperature difference across the front appear to be the main driving force behind interannual variability of the gradient (Fig. 9c). Visual inspection of the time series suggests that interannual changes in the temperature difference, rather than the width are better correlated with gradient variability at this time scale. The main exception occurs between mid 1998 and 2001 when the pronounced increase in gradient is driven by a decrease in the frontal width. The temperature range at this time is high $\left(>2.3^{\circ} \mathrm{C}\right)$ following a rapid increase during the previous El Niño, and then starts to decrease from mid 1999 onwards.

Wavelet coherence analysis supports the existence of a teleconnection between the Southland Front and ENSO. There are bands of significant coherence at periods between 8 and 32 months for all ENSO indices used in this study. Coherence between the SOI and Niño 3.4 SST region are shown in Fig. 10. The scale averaged wavelet power spectra (not shown) over the 8-32 month period band for the SOI, Niño 4, Niño 3.4 and Niño 3 regions are all significantly positively correlated (95\% confidence) with the corresponding power spectra for the gradient $(0.70,0.67,0.73$ and 0.74 respectively). This correlation increases $(>0.8)$ when the frequency band is narrowed to 16-32 months.

With the exception of a disruption around 1994, the relative phase between the gradient and ENSO indices, over regions of significant coherence, is consistent. The mean negative relative phase relationships $( \pm 1 \mathrm{sd})$ with the Niño SST regions $4,3.4$ and 3 ($139 \pm 1.5^{\circ},-149.7 \pm 1.2^{\circ}$ and $-134.8 \pm 1.1^{\circ}$ respectively), for all correlations outside the COI and above the $95 \%$ confidence interval, suggest that the gradient leads changes in the equatorial SST by 6-12 months. The SOI-gradient phase relationship however is positive $\left(77.6 \pm 1.4^{\circ}\right)$ indicating the SOI leading gradient variability by $3-7$ months. There is a marked change in the phase relationships between ENSO indices and the temperature at the front pre- and post-1994 (Figs. 10a-b). Note that, the phase relationships can always be interpreted in the opposite sense. Therefore, further evidence, provided here using cross correlations, is required to reinforce confidence in any lead or lag relationships.

The cross correlation results for seasonally averaged estimates of the Southland Front's mean temperature, gradient and temperature difference with the corresponding SOI and 
Niño 3.4 SST indices are shown in Fig. 11. The gradient and temperature difference are both significantly positively correlated at the $95 \%$ level with the SOI (Fig. 11c and e), and negatively correlated with the Niño 3.4 SST (Fig. 11d and f) when the ENSO indices lag changes at the front by 1-2 seasons (3-6 months). This implies that a weakening (strengthening) of the gradient is followed 3-6 months later by a decrease (increase) in the SOI and warming (cooling) across the equatorial Pacific. Changes in the gradient leading Pacific SST anomalies is consistent with the negative phase relationships shown by the wavelet analysis. The opposite lag response is observed for the mean frontal temperature; ENSO variability and the temperature are most highly correlated when the SOI and Niño SST anomalies lead by two seasons (Fig. 11a and b). This result in not clearly shown in Fig. 10. The same lag being significant for all examples reinforces confidence that these are real physical connections rather than anomalous, chance results. No significant lagged correlations for seasonally averaged width estimates are observed supporting the conclusion that changes in the tempeature range primariliy control interannual variability in frontal strength.

Correlation between the temperature and strength of the Southland Front, and ENSO is seasonally dependent. Once data has been seasonally stratified, the temperature is significantly positively correlated with the SOI, and negatively correlated with the Niño SST regional anomalies during the summer (Table 2). Although correlations during the spring, autumn and winter are, for the majority of cases, of the same sign, only a few were significant at the $95 \%$ level and for clarity have not been shown. Notably, correlation between the temperature and the SOI is weakest during the winter; -0.01 at zero lag and 0.07 at a one season lead. This is consistent with Mullan (1998) who found correlations between the SST and atmospheric circulation to be markedly weaker during the winter.

When spring ENSO indices are compared with the following summers mean frontal temperature the correlations remain high and significant (Table 2), reinforcing the seasonally averaged cross correlations in Fig. 11. There is a notable increase in correlation with the SOI, from 0.48 (95\% significance) to 0.63 (99\% significance), when a one season lead is introduced. 
Seasonally stratified gradient correlations reveal differences between the summer and winter (Table 3), suggesting that the relationship between ENSO and the strength of the Southland Front is dependent upon the season in which an event occurs. Temporarily ignoring the summer, the strongest correlations between the SOI and gradient (positive), and the Niño SST regions and gradient (negative), occur in the winter. During an El Niño therefore, when warm SST anomalies are observed across the central equatorial Pacific, the gradient at the front is weaker than normal (vice versa during La Niña). These winter correlations increase when a 1-2 season lag is introduced, i.e. when winter gradients are compared to equatorial SSTs or the SOI the following spring and summer. This is consistent with Fig. 11c-f. Again, repetition of the same lead-lag relationship increases confidence in the findings.

Interestingly, during the summer, the sign of ENSO-gradient correlations is reversed, suggesting that an El Niño event should result in a strengthening of the front between December and February. For equatorial SST regions 3 and 3.4 these positive correlations are significant when spring anomalies in the Pacific are correlated with the fronts gradient the following summer (a one season lead in Table 3). Spring and autumn are not shown since no significant correlations appear.

Interannual variability in the position of the front (not shown) is small owing to the strong topographic control of the continental slope. Fluctuations in the stability are more pronounced but are not correlated with El Niño or La Niña events.

\subsection{Potential physical mechanisms}

Positive correlation between the SOI and SST anomalies around New Zealand has been observed in previous studies (Greig et al., 1988; Gordon, 1986; Mullan, 1998) and can be explained in terms of the atmospheric circulation, through a combination of advection and heat fluxes. More northerly sector airflow during positive SOI events advects warm surface water and air southward. Heat fluxes from the ocean to the atmosphere are reduced because of the warm overlying air and generally lighter winds, resulting in higher SSTs. Conversely, during El Niño stronger and colder southerly winds blow cold water into the region and ocean to atmosphere heat fluxes increase (Basher and Thompson, 
1996).

From a seasonal perspective, like the temperature of the Southland Front (Table 2), mean sea level pressure around New Zealand is significantly positively correlated with the SOI during the summer (Gordon, 1986). For a negative SOI index a low pressure anomaly with clockwise rotating winds lies across South Island, under which skies will be cloudier and less radiation will reach the sea surface, promoting cooling. A positive summer SOI would lead to an anticyclonic anomaly, clearer skies, increased radiation and warming. Additionally, summer stratification results in surface waters being more sensitive to anomalous winds and heat fluxes.

Significant correlations where ENSO indices lead the temperature at the front by 3-6 months (Table 2 and Fig. 11) is suggestive of a slower, oceanic connection, in addition to the more rapid heat fluxes driven by atmospheric changes. The Coral and northern Tasman Sea experience the greatest ENSO related SST anomalies (Mullan, 1998). Assuming a conservative southerly current speed across the Tasman Sea of $0.2 \mathrm{~m} \cdot \mathrm{s}^{-1}$ (Mullan, 1998) it would take approximately 3-4 months for strong ENSO related SST anomalies in the Coral Sea to be advected to the southern tip of South Island, and into the northward flowing Southland Current. This advection time is the right order of magnitude to fit with the observed one season lead-lag times.

Identification of key mechanisms driving changes in the gradient of the front is less certain. Interannual variability is predominantly driven by changes in the temperature difference across the front. Advection and entrainment of warm (La Niña) and cold (El Niño) anomalies from the Tasman Sea, as described above, would lead to increases and decreases respectively in the temperature difference and therefore also the gradient.

SST gradients at large scale fronts can be used as a proxy for zonal velocity (Dong et al., 2006), therefore a weakening of the gradient during El Niño is suggestive of reduced velocity. Evidence of reduced flow following an El Niño has been found for other major currents in the Australasian and Indonesian region. In 1992 reduced southward flow and transport in the East Australian Current between Brisbane and Fiji coincided with an El Niño event (Sprintall et al., 1995). Maximum and minimum geostrophic transports, 
representative of the Indonesian Throughflow, were also recorded during the La Niña of 1988-1989, and the El Niños of 1986-1987 and 1991-1994 respectively (Meyers, 1996).

The anomalous increase in gradient during the 1997/1998 El Niño (Fig. 9b) can not be explained by the advection of amomalous cold subtropical water from the Tasman Sea and is inconsistent with a reduction in flow. A rapid divergence in the temperature of subantarctic and subtropical waters (Fig. 9c) implies that, contrary to the expected cooling, subtropical waters along the east coast of South Island were anomalously warm. Globally, the development and decay of the very strong and sudden 1997/1998 El Niño was not well predicted (McPhaden, 1999), and in fact warmer than usual conditions were recorded around the north-east coast of New Zealand (Basher and Thompson, 1996; Goring and Bell, 1999; Sutton and Roemmich, 2001). The 1998 'warm pool' described by Sutton and Roemmich (2001) was thought to be the result of the East Australian Current advecting more warm water into the region than the East Auckland Current was able to remove. These conditions are opposite to those described by Sprintall et al. (1995) that explain the 1992 cooling which suggests that this signal is likely not to be ENSO related. A warm anomaly would, though advection, result in the gradient increase that we observe here.

Wavelet analysis, cross correlation and an examination of the raw time series all show that changes in the gradient lead ENSO indices by 3-12 months. Why the gradient of the front should change so far in advance of El Niño and La Niña events is unclear. A possible explanation may lie in the mid-latitude pressure changes during austral winter and spring in the southwest Pacific that lead extremes in the Southern Oscillation and equatorial Pacific warming by six months (Stephens et al., 2007; Van Loon and Shea, 1985). During the winter six months before an El Niño the South Pacific trough in surface westerlies centered over Australia is enhanced. Anomalous high pressure and anomalous southwesterly wind stress drives colder water through the Tasman Sea towards the western Equatorial Pacific. This could result in a cooling of subtropical waters feeding into the Southland Current, a subsequent reduction in temperature difference across the front, and therefore a weakened gradient six months in advance of the summer El Niño. The opposite 
is true during the winter six months preceding La Niña; the trough is depressed and anomalous north-easterly winds push warm water into the Tasman Sea helping to increase temperature gradients across the Southland Front six months in advance of extremes in ENSO indices.

\section{Conclusions}

A new front detection algorithm has allowed us to examine in detail, from a $4 \mathrm{~km}$ resolution AVHRR SST data set, the seasonal, spatial and interannual changes in the position, temperature and strength of the Southland Front.

Interaction between a number of possible driving mechanisms determines variability: the magnitude and phase of the seasonal cycle in water mass temperatures; the entrainment of inshore subtropical waters whose thermohaline properties are modified by the shallow water depth, riverine input and local climatic effects; stability and mixing along the front; seasonal stratification and divergence of flow northwards. The seasonal distribution of surface water masses and the potential masking of subtropical current waters should also be considered.

The strength of the front decreases northward as it approaches the Chatham Rise driven by a general increase in width and decrease in temperature range. This is consistent with an increase in meandering intensity as the isobaths diverge and topographic control weakens. Over the extraction window selected for this study, the front was strongest in the winter and summer. These strong gradients suggest that the velocity of the Southland Current would also be increased. Considering that subantarctic waters transported within the current help maintain the STF across the Chatham Rise and western Pacific (Hurlburt et al., 2008; Sutton, 2001), it would seem reasonable that this feature is stronger and more stable during these months of increased flow.

The subtropical front and convergence are highly productive regions (Bradford-Grieve et al., 1997), they are a barrier to the distribution of marine species (Jackson et al., 2000), and a carbon dioxide sink on seasonal timescales (Currie and Hunter, 1998). Changes to the frontal structure, such as a northward increase in meandering intensity, that promote 
cross frontal mixing and the exchange of nutrients will increase biological activity, species distribution and carbon dioxide drawdown. On the other hand, where horizontal gradients are strongest, the exchange of nutrients and species such as squid across the front becomes more difficult.

The strength of the Southland Current has been shown to vary on interannual timescales, and is correlated to ENSO variability. Responses however appear to be seasonally dependent, just as there is marked seasonal variation in the pattern of other geophysical responses to ENSO (Gordon, 1986; Mullan, 1998). Broadly speaking, SST gradients decrease during El Niño and increase with La Niña. This is primarily thought to be the result of changes in the temperature of subtropical waters advected into the region from the Tasman Sea. Changes in frontal gradient are seen to take place up to 6 months in advance on peak ENSO indices. Conversely, maximum and minimum mean frontal temperature anomalies tend to lag maximum ENSO variability by 3-6 months. The physical mechanisms driving these changes are unclear and presented speculatively here.

The exact response of the Southland Front to ENSO is always going to be difficult to predict. Each event is different: they develop at different speeds and times, are initiated by different triggers and decay at different rates. The magnitude and distribution of SST anomalies across the equatorial Pacific also vary between events and do not always coincide with peak SOI values (McPhaden, 1999; Trenberth and Tepaniak, 2001; Wang et al., 2001). The season within which ENSO events develop may also play a determining role in the timing and magnitude of ocean-atmosphere responses. Furthermore, other modes of climate variability such as the Pacific Decadal Oscillation and the Antarctic Oscillation may modify the timing and magnitude of any response (Folland et al., 2002; Gershunov and Barnett, 1998; Power et al., 1999).

\section{Acknowledgments}

This work was completed by J. Hopkins while studying for a doctorate at Southampton University, UK. Funding was provided by the National Environment Research Council. Wavelet analysis software was provided by A.Grinstead and is available at http://www.pol.ac.uk/home/research/waveletcoherence/. The authors wish to thank 
Steve Chiswell for allowing use of CTD data collected on NIWA cruise 3006 in April 1993. Thanks also to three anonymous reviewers whose comments helped improve this work. 


\section{References}

Basher, R. E., Thompson, C. S., 1996. Relationship of air temperatures in New Zealand to regional anomalies in sea-surface temperature and atmospheric circulation. Int. J. Climatol. 16 (4), 405-425.

Belkin, I. M., Gordon, A. L., 1996. Southern Ocean fronts from the Greenwich meridian to Tasmania. J. Geophys. Res - Oceans 101 (C2), 3675-3696.

Boyd, P., La Roche, J., Gall, M., Frew, R., McKay, R. M. L., 1999. Role of iron, light, and silicate in controlling algal biomass in subantarctic waters SE of New Zealand. J. Geophys. Res - Oceans 104 (C6), 13395-13408.

Bradford-Grieve, J. M., Chang, F. H., Gall, M., Pickmere, S., Richards, F., 1997. Sizefractionated phytoplankton standing stocks and primary production during austral winter and spring 1993 in the Subtropical Convergence region near New Zealand. N. Z .J. Mar. Freshwater Res. 31 (2), 201-224.

Brodie, J., 1960. Coastal surface currents around New Zealand. N. Z. J. Geol. Geophys. $3,235-252$.

Butler, E. C. V., Butt, J. A., Lindstrom, E. J., Tildesley, P. C., Pickmere, S., Vincent, W. F., 1992. Oceanography of the Subtropical Convergence Zone around Southern New-Zealand. N. Z. J. Mar. Freshwater Res. 26 (2), 131-154.

Chiswell, S. M., 1994. Variability in sea-surface temperature around New-Zealand from AVHRR images. N. Z. J. Mar. Freshwater Res. 28 (2), 179-192.

Chiswell, S. M., 1996. Variability in the Southland Current, New Zealand. N. Z .J. Mar. Freshwater Res. 30 (1), 1-17.

Currie, K. I., Hunter, K. A., 1998. Surface water carbon dioxide in the waters associated with the subtropical convergence, east of New Zealand. Deep-Sea Res. Part I-Oceanographic Research Papers 45 (10), 1765-1777. 
Currie, K. I., Hunter, K. A., 1999. Seasonal variation of surface water $\mathrm{CO}_{2}$ partial pressure in the Southland Current, east of New Zealand. Mar. Freshwater Res. 50 (5), 375-382.

Dong, S., Sprintall, J., Gille, S. T., 2006. Location of the Antarctic Polar Front from AMSR-E satellite surface temperature measurements. J. Phys. Oceanogr. 36, 20752089.

Emery, W., Thomson, R., 1998. Data Analysis Methods in Physical Oceanography. Permagon Press, Oxford.

Folland, C. K., Renwick, J. A., Salinger, M. J., Mullan, A. B., 2002. Relative influences of the Interdecadal Pacific Oscillation and ENSO on the South Pacific Convergence Zone. Geophys. Res. Lett 29 (13), doi:10.1029/2001GL014201.

Gershunov, A., Barnett, T. P., 1998. Interdecadal modulation of ENSO teleconnections. Bull. Amer. Meteor. Soc. 79 (12), 2715-2725.

Gordon, N. D., 1986. The Southern Oscillation and New-Zealand weather. Mon. Wea. Rev. 114 (2), 371-387.

Goring, D. G., Bell, R. G., 1999. El Niño and decadal effects on sea-level variability in northern New Zealand: a wavelet analysis. N. Z .J. Mar. Freshwater Res. 33 (4), $587-598$.

Greig, M. J., Gilmour, A. E., 1992. Flow through the Mernoo Saddle, New-Zealand. N. Z. J. Mar. Freshwater Res. 26 (2), 155-165.

Greig, M. J., Ridgway, N. M., Shakespeare, B. S., 1988. Sea-surface temperaturevariations at coastal sites around New-Zealand. N. Z .J. Mar. Freshwater Res. 22 (3), $391-400$.

Grinsted, A., Moore, J. C., Jevrejeva, S., 2004. Application of the cross wavelet transform and wavelet coherence to geophysical time series. Nonlin. Proc. In Geophys. 11 (5-6), $561-566$. 
Heath, R. A., 1972. The Southland Current. N. Z. J. Mar. Freshwater Res. 6, 497-533.

Heath, R. A., 1985. A review of the physical oceanography of the seas around NewZealand - 1982. N. Z. J. Mar. Freshwater Res. 19 (1), 79-124.

Hopkins, J., 2008. Statistical modelling and variability of the Subtropical front, New Zealand. Ph.D. thesis, School of Ocean and Earth Science, Southampton University, UK.

Hopkins, J., Challenor, P., Shaw, A., 2010. A new statistical modelling approach to ocean front detection from SST satellite images. J. Atmos. Oceanic Technol. 27 (1), 173-191.

Houtman, J., 1966. A note on the hydrological regime in Foveaux Strait. N. Z. J. Sci. 9, $472-483$.

Hurlburt, H. E., Metzger, E. J., Hogan, P. J., Tilburg, C. E., Shriver, J. F., 2008. Steering of upper ocean currents and fronts by the topographically constrained abyssal circulation. Dyn. Atmos. Oceans 45 (3-4), 102-134.

Jackson, G. D., Shaw, A. G. P., Lalas, C., 2000. Distribution and biomass of two squid species off southern New Zealand: Nototodarus sloanii and Moroteuthis ingens. Polar Biol. 23 (10), 699-705.

Jillett, J., 1969. Seasonal hydrology of waters off the Otago Peninsula, south-eastern New Zealand. N. Z. J. Mar. Freshwater Res. 3 (3), 349-375.

Kilpatrick, K. A., Podesta, G. P., Evans, R., 2001. Overview of the NOAA/NASA advanced very high resolution radiometer Pathfinder algorithm for sea surface temperature and associated matchup database. J. Geophys. Res - Oceans 106 (C5), 9179-9197.

Lee, T., Cornillon, P., 1995. Temporal variation of meandering intensity and domain-wide lateral oscillations of the Gulf-Stream. J. Geophys. Res - Oceans 100 (C7), 13603-13613.

Livingston, M. E., 2000. Links between climate variation and the year class strength of New Zealand hoki (Macruronus novaezelandiae) Hector. N. Z. J. Mar. Freshwater Res. $34(1), 55-69$. 
McClatchie, S., Coombs, R., Macaulay, G., 2001. Bugs, physics and production in the Subtropical Front. Water Atmos. 9 (3), 19-21.

McPhaden, M. J., 1999. Genesis and evolution of the 1997-98 El Niño. Science 283 (5404), 950-954.

Meyers, G., 1996. Variation of Indonesian throughflow and the El Niño Southern Oscillation. J. Geophys. Res. - Oceans 101 (C5), 12255-12263.

Mullan, A. B., 1998. Southern hemisphere sea-surface temperatures and their contemporary and lag association with New Zealand temperature and precipitation. Int. J. Climatol. 18 (8), 817-840.

Murdoch, R. C., Proctor, R., Jillett, J. B., Zeldis, J. R., 1990. Evidence for an eddy over the continental-shelf in the downstream lee of Otago Peninsula, New Zealand. Estuarine Coastal Shelf Sci. 30 (5), 489-507.

Murphy, P. P., Feely, R. A., Gammon, R. H., Harrison, D. E., Kelly, K. C., Waterman, L. S., 1991. Assessment of the air-sea exchange of $\mathrm{CO}_{2}$ in the South-Pacific during austral autumn. J. Geophys. Res - Oceans 96 (C11), 20455-20465.

Power, S., Casey, T., Folland, C., Colman, A., Mehta, V., 1999. Inter-decadal modulation of the impact of ENSO on Australia. Climate Dynamics 15 (5), 319-324.

Priestley, M., 1992. Spectral Analysis and Time Series. Probability and Mathematical Statistics. Academic Press, London.

Shaw, A. G. P., 1998. The temporal and spatial variability of the Southland Front, New Zealand using AVHRR SST imagery. Ph.D, University of Otago, Dunedin, New Zealand.

Shaw, A. G. P., Kavalieris, L., Vennell, R., 1999. Seasonal and inter-annual variability of SST off the east coast of the South Island, New Zealand. Geocarto Int. 14 (3), 27-32.

Shaw, A. G. P., Vennell, R., 2000a. A front-following algorithm for AVHRR SST imagery. Remote Sens. Environ. 72 (3), 317-327. 
Shaw, A. G. P., Vennell, R., 2000b. Variability of water masses through the Mernoo Saddle, South Island, New Zealand. N. Z .J. Mar. Freshwater Res. 34 (1), 103-116.

Shaw, A. G. P., Vennell, R., 2001. Measurements of an oceanic front using a front-following algorithm for AVHRR SST imagery. Remote Sens. Environ. 75 (1), 47-62.

Silverman, B., 1986. Density Estimation for Statistics and Data Analysis. Monographs on Statistics and Applied Probability. Chapman and Hall, London.

Sprintall, J., Roemmich, D., Stanton, B., Bailey, R., 1995. Regional climate variability and ocean heat-transport in the southwest Pacific-Ocean. J. Geophys. Res. - Oceans 100 (C8), 15865-15871.

Stephens, D. J., Meuleners, M. J., Van Loon, H., Lamond, M. H., Telcik, N. P., 2007. Differences in atmospheric circulation between the development of weak and strong warm events in the Southern Oscillation. J. Climate 20 (10), 2191-2209.

Sutton, P., 2001. Detailed structure of the Subtropical Front over Chatham Rise, east of New Zealand. J. Geophys. Res - Oceans 106 (C12), 31045-31056.

Sutton, P. J. H., 2003. The Southland Current: a subantarctic current. N. Z .J. Mar. Freshwater Res. 37 (3), 645-652.

Sutton, P. J. H., Roemmich, D., 2001. Ocean temperature climate off north-east New Zealand. N. Z .J. Mar. Freshwater Res. 35 (3), 553-565.

Tilburg, C. E., Hurlburt, H. E., O’Brien, J. J., Shriver, J. F., 2002. Remote topographic forcing of a baroclinic western boundary current: An explanation for the Southland Current and the pathway of the subtropical front east of New Zealand. J. Phys. Oceanogr. $32(11), 3216-3232$.

Torrence, C., Compo, G. P., 1998. A practical guide to wavelet analysis. Bull. Amer. Meteor. Soc. 79 (1), 61-78. 
Trenberth, K. E., Tepaniak, D. P., 2001. Indices of El Niño evolution. J. Climate 14 (8), $1697-1701$.

Uddstrom, M. J., Oien, N. A., 1999. On the use of high-resolution satellite data to describe the spatial and temporal variability of sea surface temperatures in the New Zealand region. J. Geophys. Res - Oceans 104 (C9), 20729-20751.

Van Loon, H., Shea, D. J., 1985. The Southern Oscillation .4. The precursors south of $15^{\circ} \mathrm{S}$ to the extremes of the oscillation. Mon. Wea. Rev. 113 (12), 2063-2074.

Wang, D. X., Liu, Y., Qi, Y. Q., Shi, P., 2001. Seasonal variability of thermal fronts in the northern South China Sea from satellite data. Geophys. Res. Lett 28 (20), 3963-3966. 

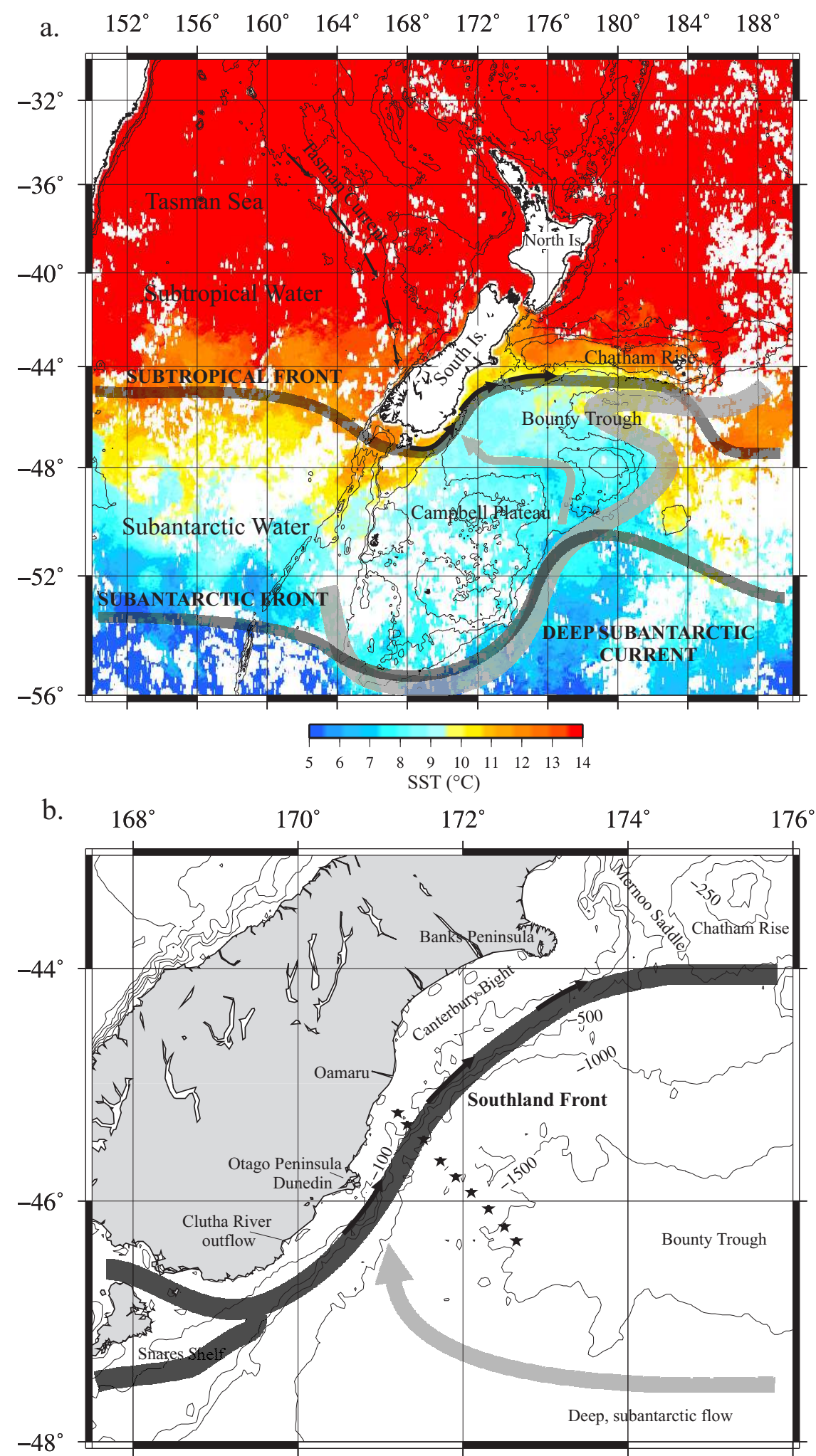

Figure 1: (a) The approximate positions of the Subtropical and Subantarctic Fronts (dark grey), and deep subantarctic currents (light grey) around South and North Islands, New Zealand. Sea surface temperatures $\left({ }^{\circ} \mathrm{C}\right.$ ) are for June 2004. (b) Location of the Southland Front off South Island. Black contours show the bathymetry $(\mathrm{m})$. Black stars $\mathrm{ma}^{30 \mathrm{k}}$ the CTD casts from NIWA cruise 3006 in April 1993. 

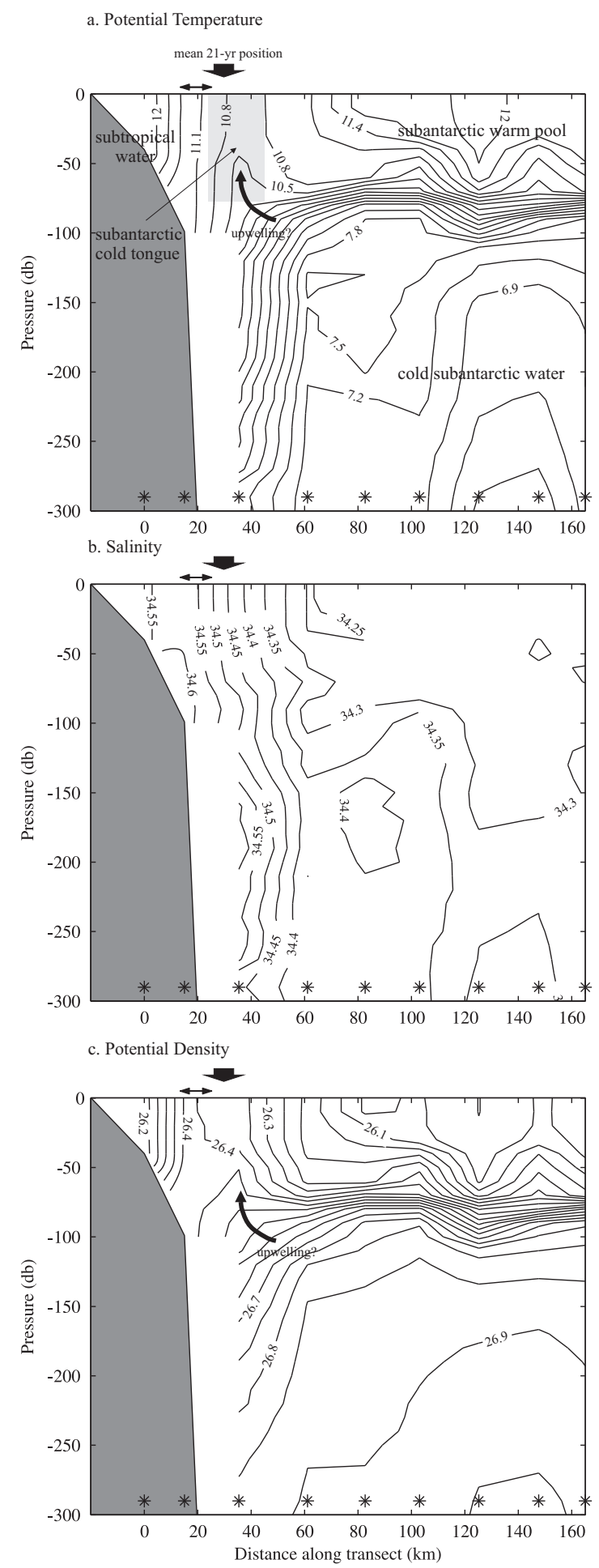

Figure 2: Hydrographic section off Oamaru from NIWA cruise 3006 April 1993. (a) Potential temperature $\left({ }^{\circ} \mathrm{C}\right)$, (b) Salinity and (c) Potential density. * mark the position of CTD casts taken over 10-11 April 1993. The mean 21-year position of the Southland Front is shown by the vertical, downward pointing arrow. The width of the arrow head represents 1 standard deviation either side of the mean. The double horizontal arrow marks the position of the Southland Front calculated from the April 1993 monthly SST composite. 


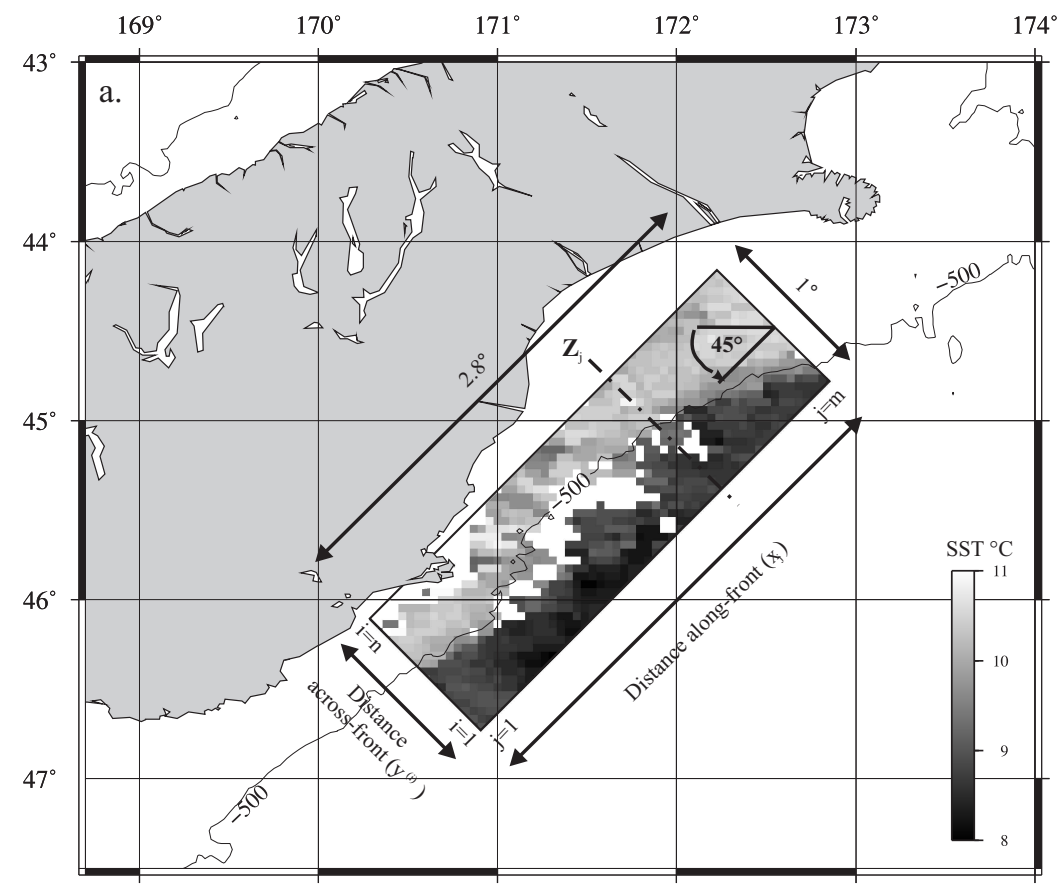

b.

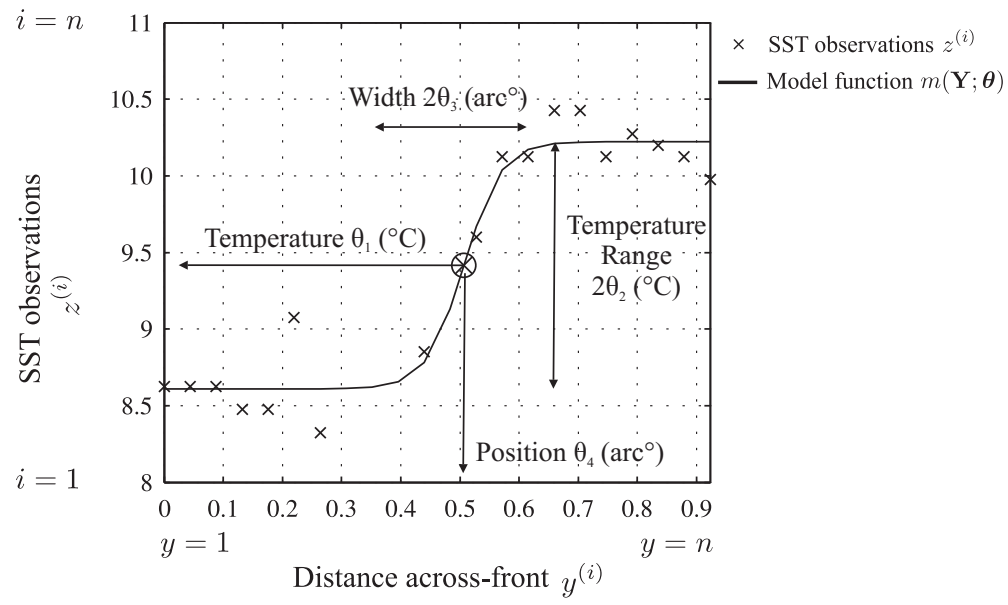

Figure 3: (a) $1^{\circ} \times 2.8^{\circ}$ extraction window, rotated by $45^{\circ}$ to lie along the $500 \mathrm{~m}$ isobath, the approximate location of the Southland Front. The dashed line marks an example cross section of SST observations $\left(\mathbf{Z}_{j}\right)$ at position $x_{j}$ along the front. (b) Physical interpretation of the model parameters $\boldsymbol{\theta}$ fitted to the SST observations $\mathbf{Z}_{j}$. 

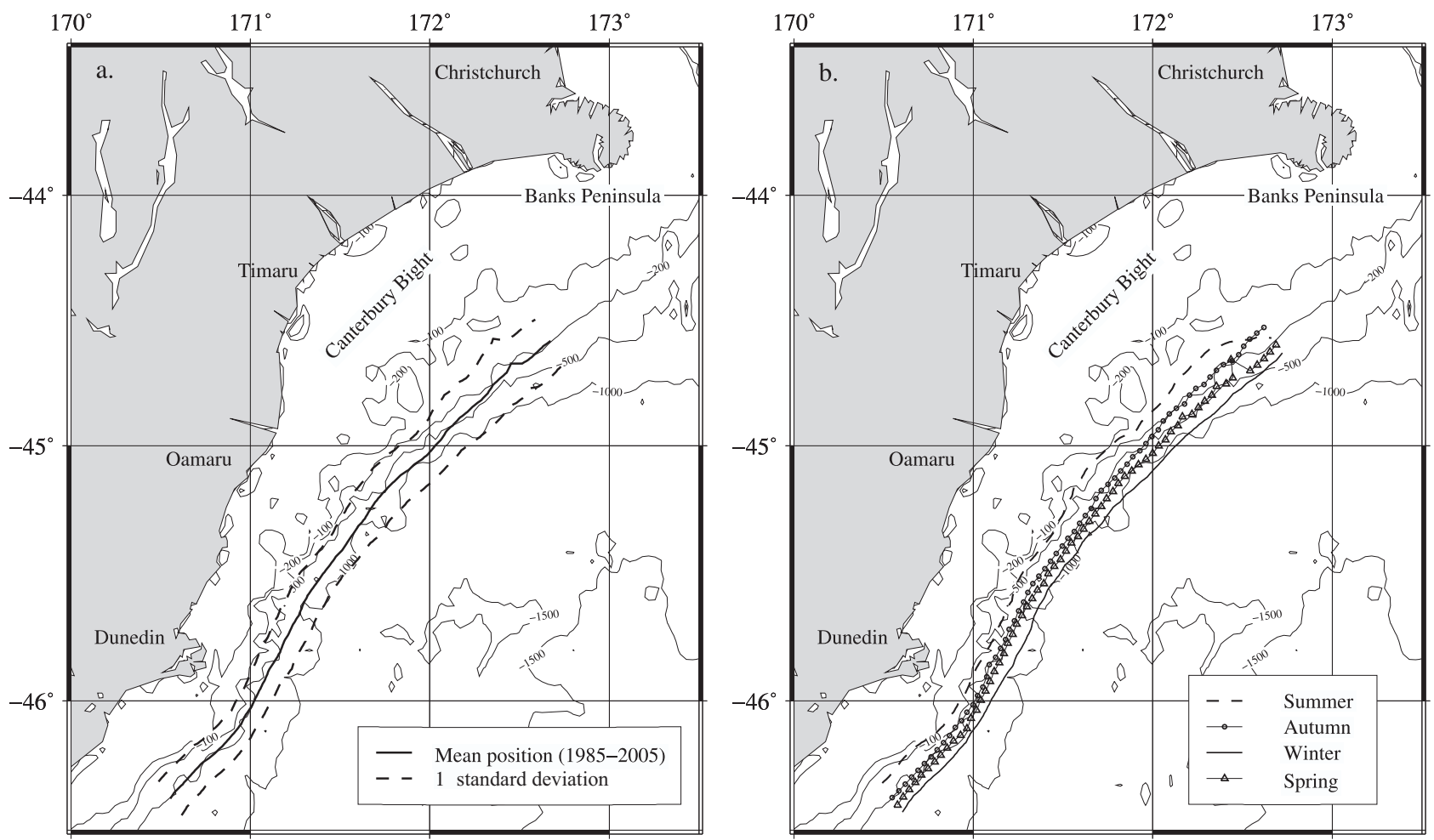

Figure 4: (a) Mean and (b) seasonal positions of the Southland Front between 1985 and 2005. 

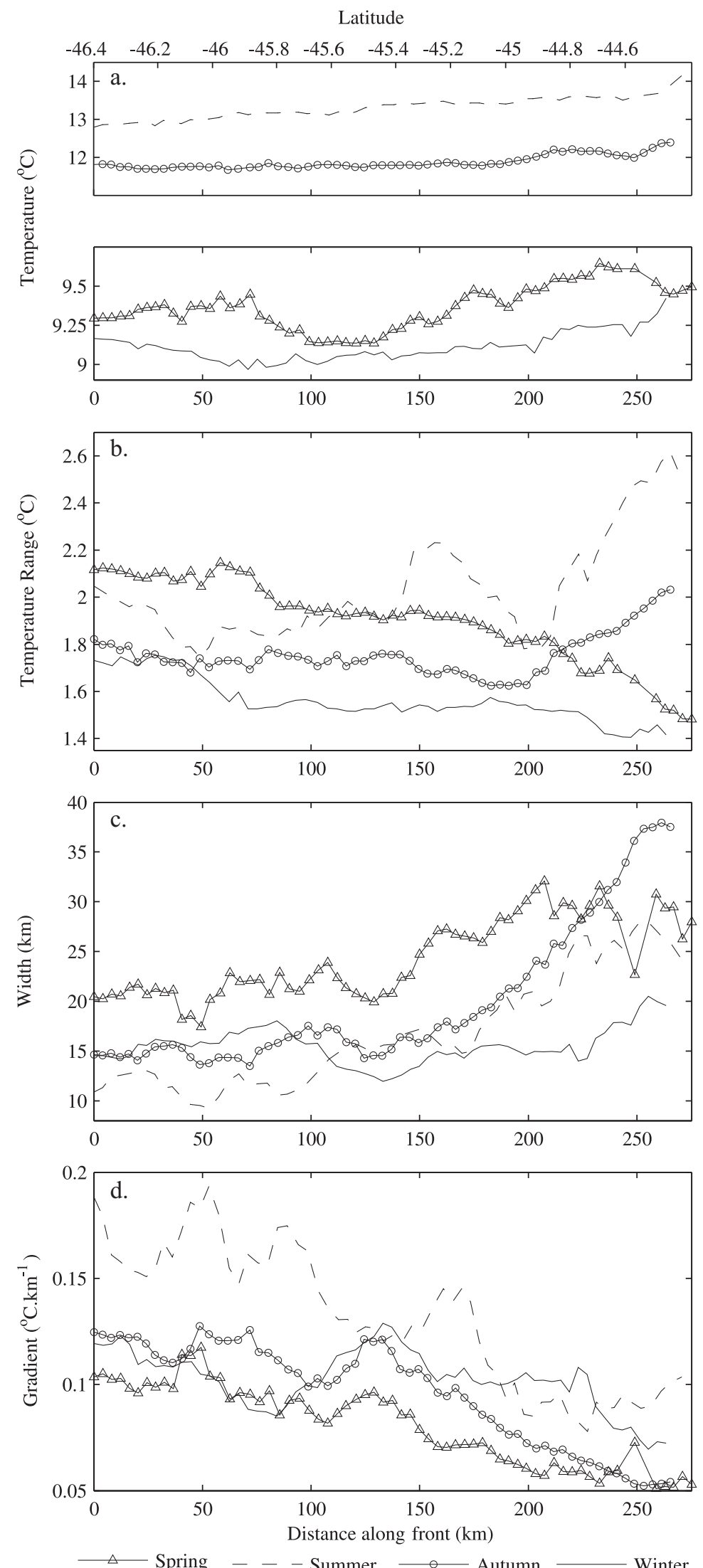

34

Figure 5: Seasonal and spatial variability of the (a) temperature, (b) temperature range, (c) width and (d) gradient of the Southland Front. 

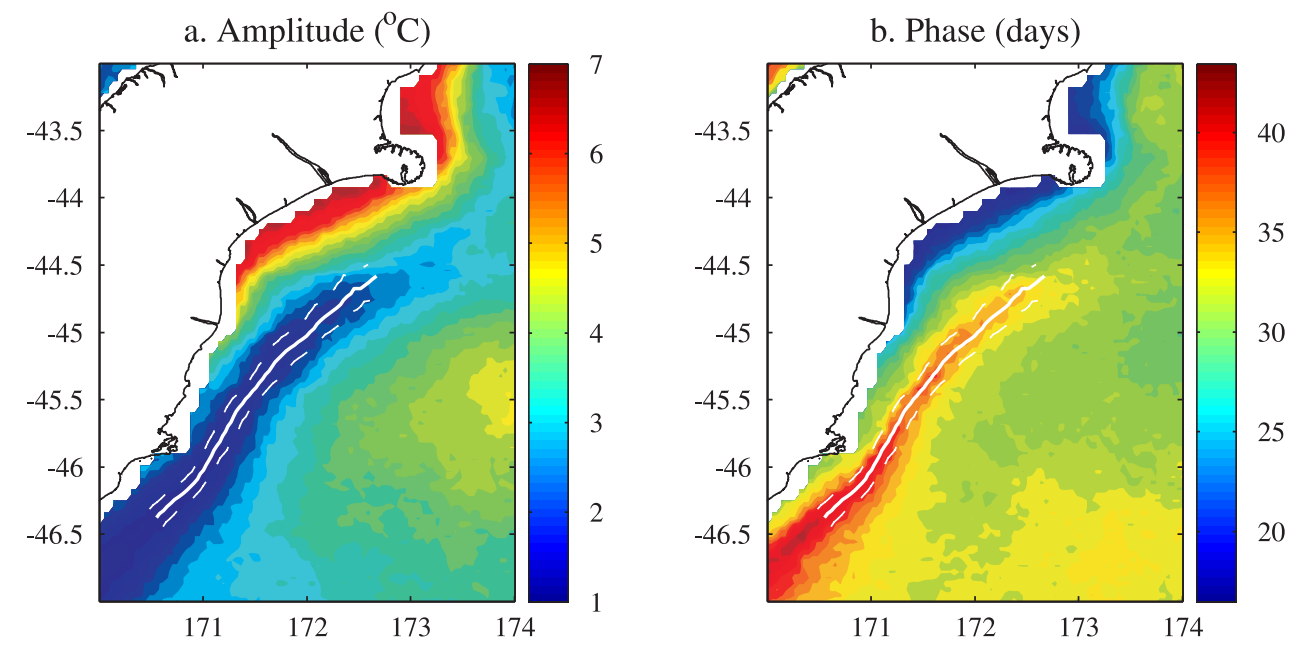

c. Gradient of amplitude $\left({ }^{\circ} \mathrm{C} 12 \mathrm{~km}^{-1}\right)$
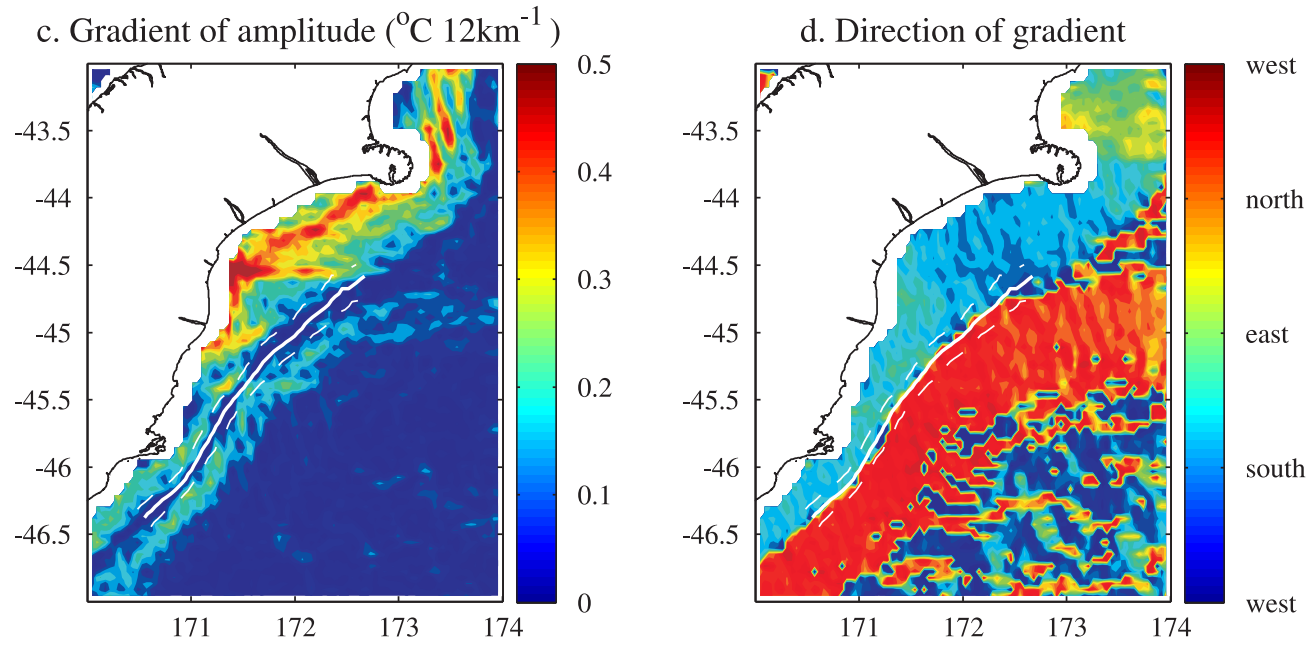

Figure 6: (a) Amplitude of the annual SST cycle. (b) Phase, expressed as the lag of the peak in days relative to $1^{\text {st }}$ January. (c) Absolute gradient of the amplitude $\left({ }^{\circ} \mathrm{C} 12 \mathrm{~km}^{-1}\right)$. (d) Direction of gradient, from high to low values of the SST range. Solid white line marks the mean 21-year position of the Southland Front \pm 1 standard deviation (dashed lines). 

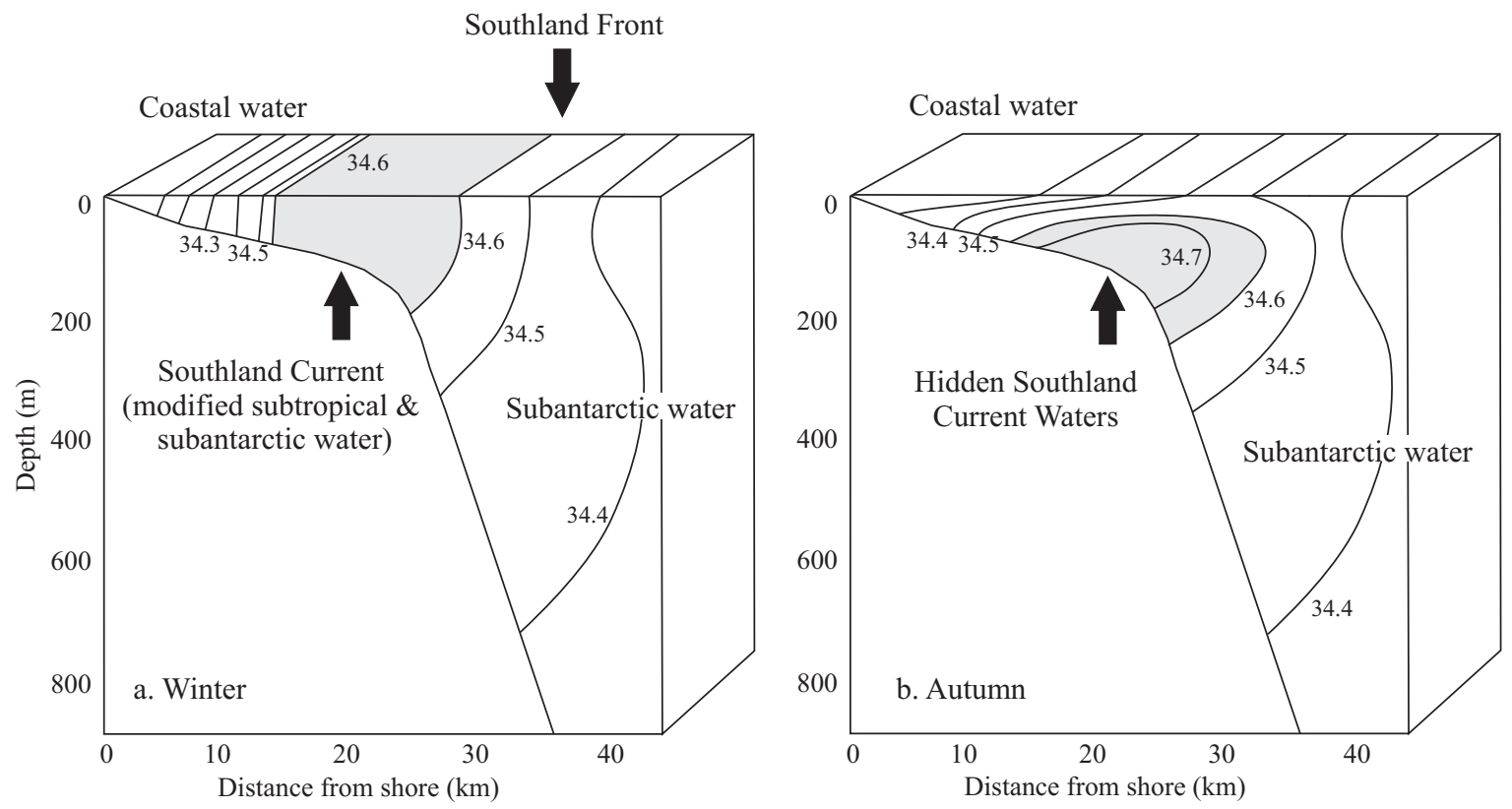

Figure 7: (a) Schematic of a vertical salinity section across the continental shelf and slope at Otago Peninsula during the winter. To the east the Southland Front separates modified subtropical shelf waters flowing northwards in the Southland Current from fresher, offshore subantarctic waters. All water masses are visible at the surface. (b) Salinity section during the autumn where Southland Current waters are hidden beneath a superficial layer of coastal and subantarctic waters. Based on vertical sections of salinity presented by Jillett (1969). 


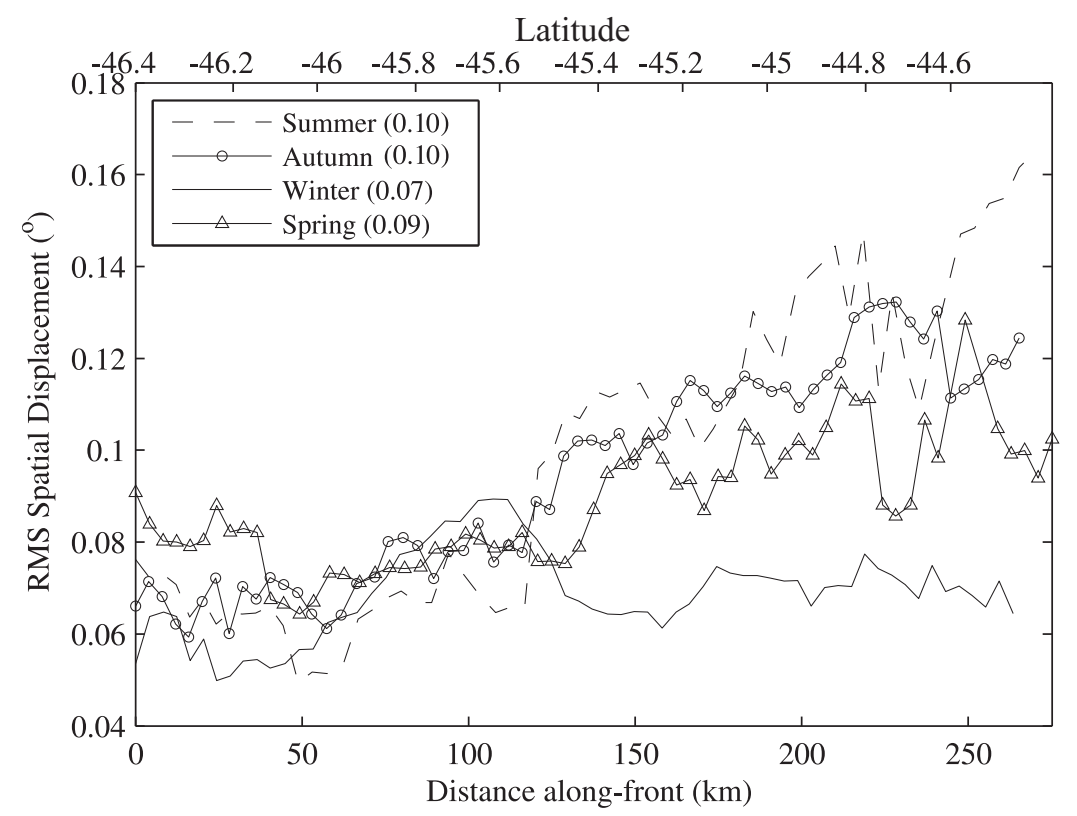

Figure 8: Seasonal and spatial variability of the meandering intensity (RMSSD) of the Southland Front. Seasonal means are enclosed between brackets in the legend. 

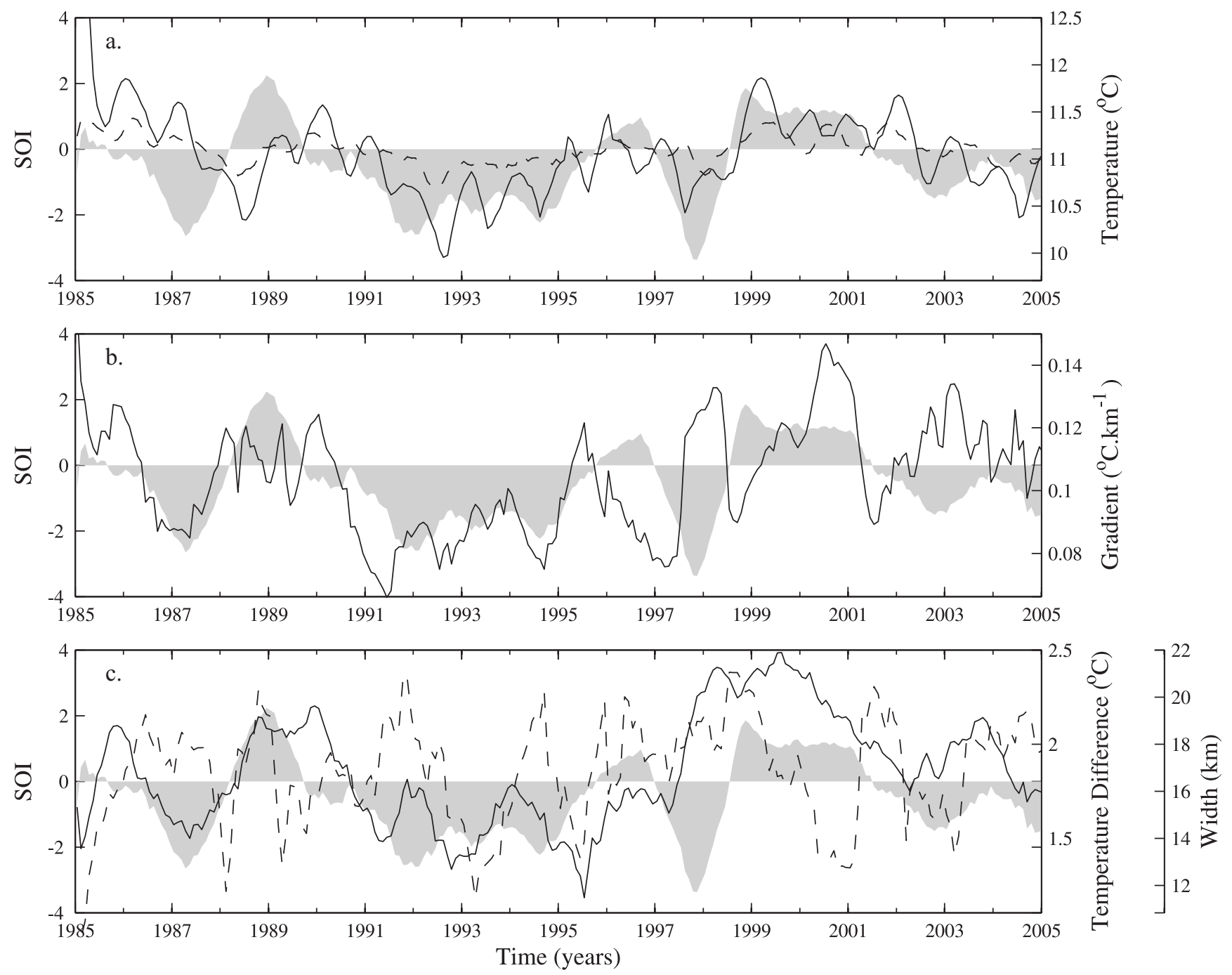

Figure 9: Twelve month running mean time series of (a) temperature (solid line), (b) gradient (solid line), (c) temperature difference (solid line) and width (dashed line) relative to a $4 \mathrm{~km}$ resolution data set. The shaded regions in each plot (a-c) are the SOI. The dashed line in (a) is a 6 month running mean of the temperature anomaly. 

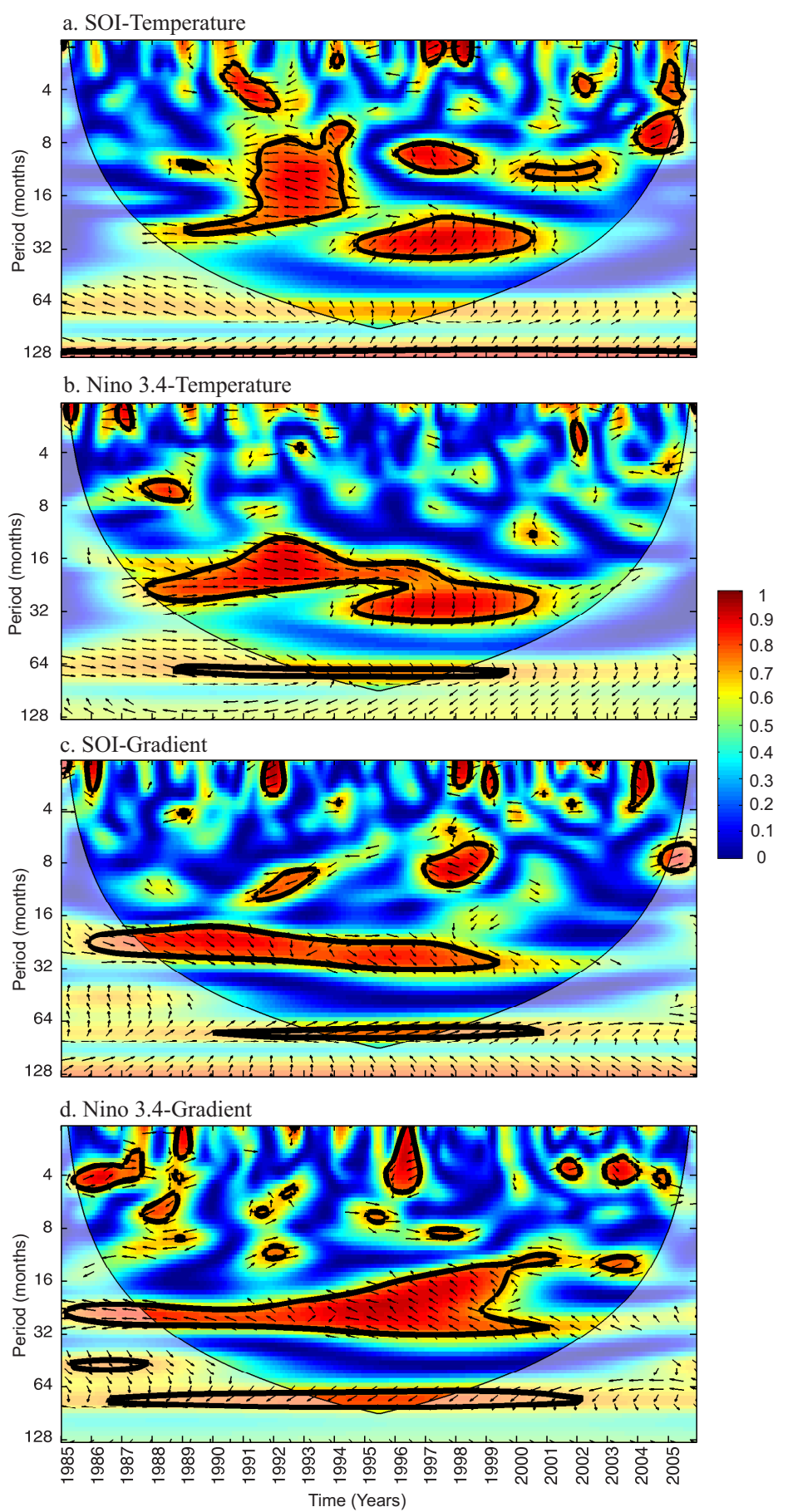

Figure 10: Wavelet squared coherence between (a) SOI and temperature, (b) Niño 3.4 and temperature, (c) SOI and gradient, (d) Niño 3.4 and gradient. Thick black contours are the $95 \%$ confidence level above a white noise background spectrum. Arrows indicate the relative phase relationship. In phase pointing right $\left(0^{\circ}\right)$, antiphase pointing left $\left( \pm 180^{\circ}\right)$, ENSO leading front by $+90^{\circ}$ straight down, front leading ENSO by $-90^{\circ}$ straight up. Faded area marks the COI. 

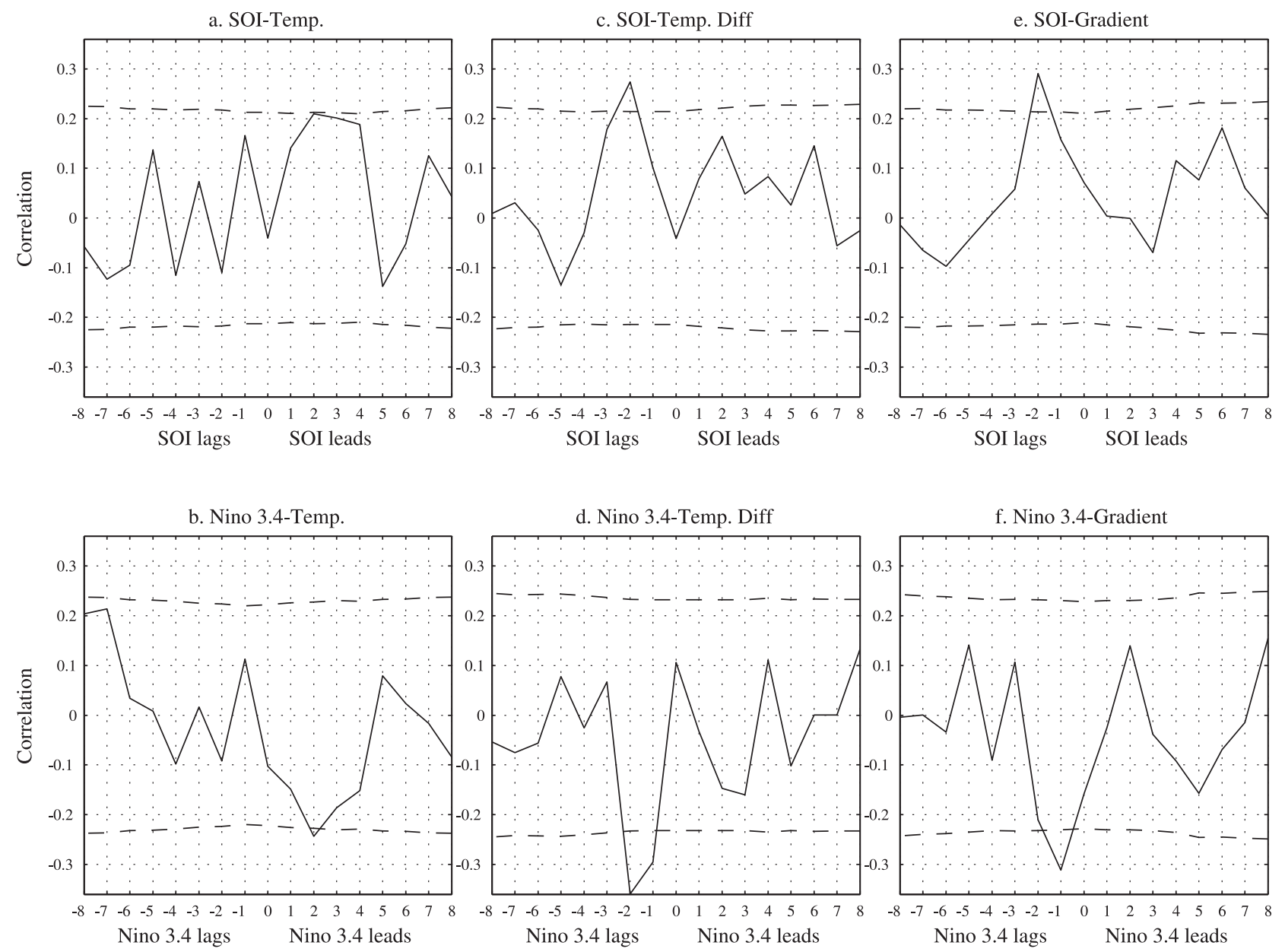

Figure 11: Cross correlations of seasonally averaged time series. SOI vs (a) temperature, (c) temperature difference and (e) gradient. Niño 3.4 SST vs (b) temperature, (d) temperature difference and (f) gradient. Lead and lag times are for seasons. Dashed lines mark the $95 \%$ confidence levels. 
Table 1: Overall (1985-2005) and seasonal mean characteristics of the Southland Front. Weighted mean $\left(\bar{\theta}_{w}\right) \pm 2 \times$ standard error of the mean $\left(2 \sigma_{\bar{\theta}_{w}}\right)$. Weighted standard deviation $\left(\bar{\sigma}_{w}\right)$ given in brackets.

\begin{tabular}{ccccc}
\hline \hline & \multicolumn{4}{c}{$\bar{\theta}_{w} \pm 2 \sigma_{\bar{\theta}_{w}}\left(\bar{\sigma}_{w}\right)$} \\
\cline { 2 - 5 } & $\begin{array}{c}\text { Temperature } \\
\left({ }^{\circ} \mathrm{C}\right)\end{array}$ & $\begin{array}{c}\text { Temperature Range } \\
\left({ }^{\circ} \mathrm{C}\right)\end{array}$ & $\begin{array}{c}\text { Width } \\
(\mathrm{km})\end{array}$ & $\begin{array}{c}\text { Gradient } \\
\left({ }^{\circ} \mathrm{C} . \mathrm{km}^{-1}\right)\end{array}$ \\
\hline \multirow{2}{*}{ 1985-2005 } & $10.38 \pm 0.001(1.80)$ & $1.75 \pm 0.001(0.51)$ & $18.00 \pm 0.044(10.70)$ & $0.097 \pm 0.003$ \\
Spring & $9.36 \pm 0.002(0.89)$ & $1.89 \pm 0.002(0.51)$ & $23.88 \pm 0.089(11.79)$ & $0.079 \pm 0.004$ \\
Summer & $13.27 \pm 0.003(1.08)$ & $1.99 \pm 0.003(0.54)$ & $15.02 \pm 0.101(10.23)$ & $0.132 \pm 0.007$ \\
Autumn & $11.87 \pm 0.002(1.14)$ & $1.74 \pm 0.002(0.52)$ & $18.02 \pm 0.086(10.89)$ & $0.097 \pm 0.005$ \\
Winter & $9.12 \pm 0.002(0.68)$ & $1.55 \pm 0.002(0.39)$ & $15.12 \pm 0.079(7.51)$ & $0.103 \pm 0.005$ \\
\hline
\end{tabular}


Table 2: Correlations between the temperature of the Southland Front, the SOI and Niño SST region 3.4 for seasonally stratified data. Only correlations significant at the $95 \%$ level and above are shown. ${ }^{\dagger}$ indicates significance at the $99 \%$ level. Seasonal leads are for the ENSO indices leading temperature at the front.

\begin{tabular}{l|cc|cc}
\hline \hline & \multicolumn{2}{|c|}{ SOI } & \multicolumn{2}{c}{ Niño 3.4 SST } \\
& 0 Lag & 1 Season Lead & 0 Lag & 1 Season Lead \\
\hline Spring & & & & \\
Summer & 0.48 & $0.63^{\dagger}$ & $-0.67^{\dagger}$ & $-0.61^{\dagger}$ \\
Autumn & & & -0.5 & $-0.60^{\dagger}$ \\
Winter & & & & \\
\hline
\end{tabular}


Table 3: Seasonally stratified correlations between the gradient of the Southland Front, the SOI and regional Niño SST anomalies. Bold face indicates significance at the $95 \%$ level. One season leads are for ENSO indices leading the gradient. One and two season lags are for ENSO indices lagging the gradient.

\begin{tabular}{|c|c|c|c|c|}
\hline & 1 lead & $0 \mathrm{lag}$ & $1 \mathrm{lag}$ & $2 \operatorname{lag}$ \\
\hline & \multicolumn{4}{|c|}{ SOI } \\
\hline Summer & -0.34 & -0.43 & -0.01 & 0.32 \\
\hline \multirow[t]{2}{*}{ Winter } & 0.49 & 0.44 & 0.58 & 0.50 \\
\hline & \multicolumn{4}{|c|}{ Niño 3.4 SST } \\
\hline Summer & 0.48 & 0.44 & 0.21 & -0.35 \\
\hline \multirow[t]{2}{*}{ Winter } & -0.37 & -0.48 & -0.57 & -0.60 \\
\hline & \multicolumn{4}{|c|}{ Niño 3 SST } \\
\hline Summer & 0.46 & 0.56 & 0.37 & -0.12 \\
\hline Winter & -0.28 & -0.37 & -0.51 & -0.60 \\
\hline
\end{tabular}

